\title{
Hydroxylamine as a superior organocatalyst for Morita-Baylis-Hillman reaction
}

\author{
Veejendra K. Yadav* \\ Department of Chemistry, Indian Institute of Technology Kanpur, Kanpur 208016, India \\ vijendra@iitk.ac.in
}

\begin{abstract}
Computational investigations indicate that the use of $\mathrm{N}, \mathrm{N}$-dimethylhydroxylamine as organocatalyst enhances the rate of Morita-Baylis-Hillman reaction by lowering the activation energy of the rate-controlling aldol step. The rate enhancement is understood to originate from the $\alpha$-effect of oxygen on nitrogen in hydroxylamine, which enhances the nucleophilicity of the nitrogen and results in its more effective conjugate addition to the enone to form an advanced and, thus, reactive enolate to participate in the aldol process. The activation energy of the aldol reaction is therefore reduced.
\end{abstract}

Keywords. Morita-Baylis-Hilman reaction, $\mathrm{N}, \mathrm{N}$-dimethylhydroxylamine, $\alpha$-effect, 2-cyclopentenone, acetaldehyde, rate-acceleration, solvent effects

\section{Introduction}

Morita-Baylis-Hillman ( $\mathrm{MBH}$ ) reaction is one of the finest examples of versatile atom-economic carbon-carbon bond-forming reactions in which an activated olefin reacts with a carbonyl species under catalysis by generally a nucleophilic tertiary amine to form an $\alpha$-hydroxyalkyl activated olefin, which serves as a very useful multifunctional building block in organic synthesis. ${ }^{1}$ The synthetic application of this reaction due to the multi-functional nature of the product is so very significant that several reports on expanding the substrate scope, catalysis by different nucleophiles in efforts to obtain high yields in less time, and development of the asymmetric version have prominently appeared in the literature. ${ }^{2}$

The reaction mechanism was long understood to involve proton transfer from the $\alpha$-carbon of the activated olefin to the alcoholate formed from aldol reaction through a four-membered transition state (TS) followed by E1cB event to generate the product as shown in Scheme $1 .^{3}$ This mechanism has lately been revised and computationally shown to follow the lower energy pathway sketched in Scheme $2 .{ }^{4}$ In this pathway, proton is transferred from an alkyl group of the ammonium ion to the 
alcoholate through a seven-membered TS structure and the resultant undergoes syn elimination in Hofmann manner to form the MBH product.

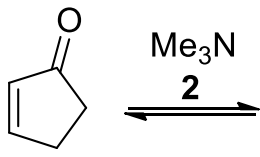

1

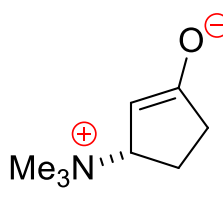

3

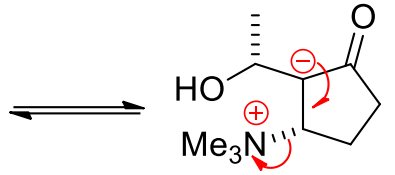

$6 a$

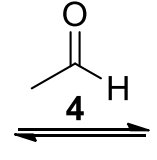

$-\mathrm{Me}_{3} \mathrm{~N}$<smiles>C[C@@H]1ON(C)[C@@H]2CCC(=O)[C@@]12[C@@H](C)O</smiles>

5<smiles>C[C@H](O)C1=CCCC1=O</smiles>

7

Scheme 1. The previously accepted pathway for the $\mathrm{Me}_{3} \mathrm{~N}$-catalysed $\mathrm{MBH}$ reaction of 2-cyclopentenone with $\mathrm{CH}_{3} \mathrm{CHO}$ involving proton transfer through a four-membered TS structure $(5 \rightarrow 6 a)$

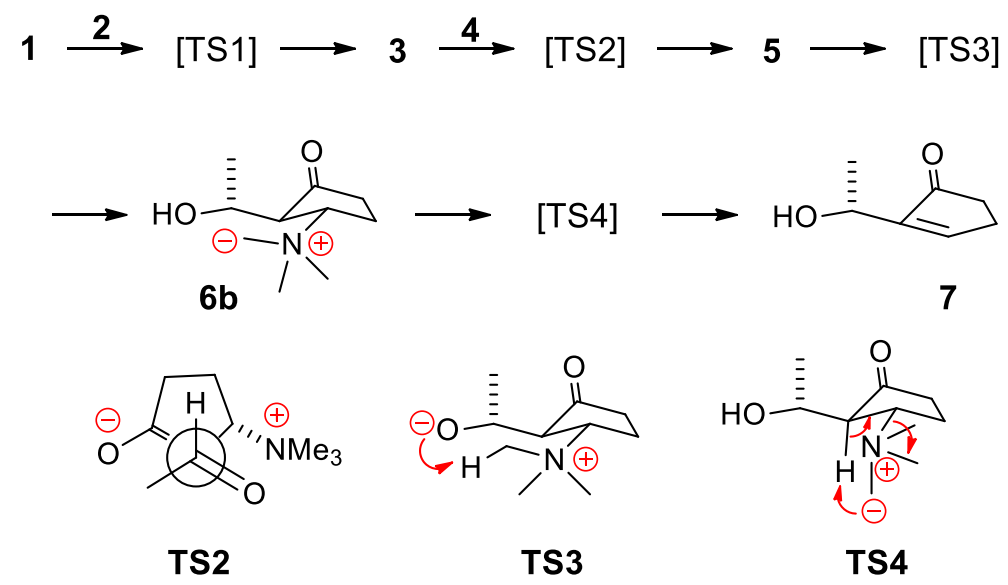

Scheme 2. The new pathway for the $\mathrm{Me}_{3} \mathrm{~N}$-catalysed $\mathrm{MBH}$ reaction of 2-cyclopentenone with $\mathrm{CH}_{3} \mathrm{CHO}_{\mathrm{O}}$ involving proton transfer through a seven-membered TS structure. TS1 = TS for conjugate addition of $\mathrm{Me}_{3} \mathrm{~N}$ to cyclopentenone, TS2 = TS for aldol reaction, TS3 = TS for proton transfer through seven-membered ring, TS4 = TS for Hofmann elimination

We reasoned that the use of hydroxylamine in place of trialkylamine was likely to enhance the reaction rate for the enhanced nucleophilicity of nitrogen due to the $\alpha$-effect ${ }^{5}$ of oxygen. Thus, the more effective conjugate addition of hydroxylamine to the activated alkene will result in a relatively more advanced and, hence, more reactive enolate to subsequently enter the rate-controlling ${ }^{3,6,7}$ aldol step. The activation energy of the aldol reaction may, therefore, diminish to result in a faster reaction. A careful search of the literature revealed that hydroxylamine has neither been used nor suggested before this report. Herein, we present the results of our study by taking 2-cyclopentenone as the 
activated alkene and $\mathrm{CH}_{3} \mathrm{CHO}$ as electrophile for the aldol reaction under catalysis by $\mathrm{N}, \mathrm{N}$ dimethylhydroxylamine $\left(\mathrm{Me}_{2} \mathrm{NOH}\right)$ in following the route given in Scheme 3.

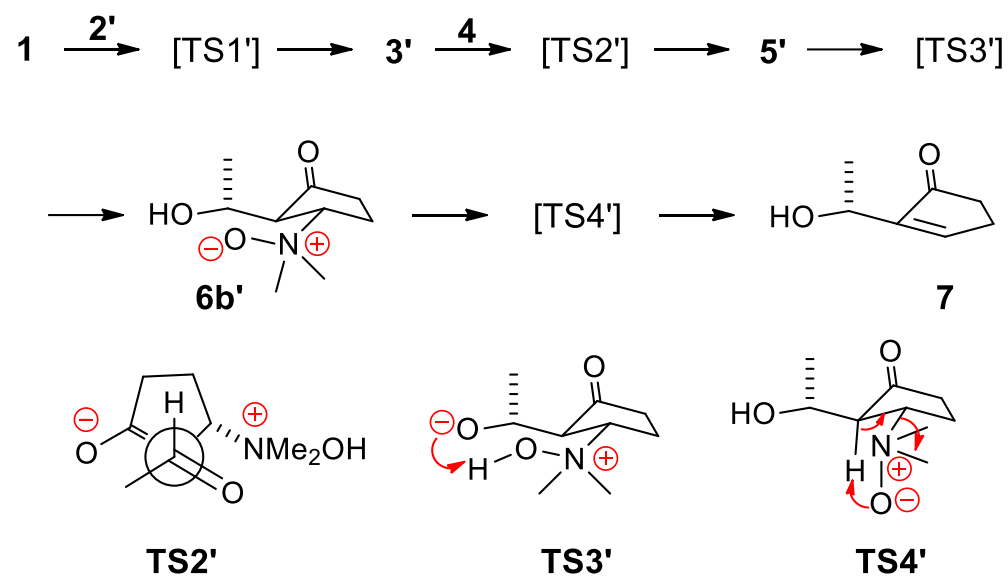

Scheme 3. $\mathrm{Me}_{2} \mathrm{NOH}$-catalysed $\mathrm{MBH}$ reaction of 2-cyclopentenone with $\mathrm{CH}_{3} \mathrm{CHO}$. 2' $=\mathrm{Me}_{2} \mathrm{NOH}, \mathbf{3}^{\prime}=$ enolate formed from conjugate addition of $\mathrm{Me}_{2} \mathrm{NOH}$ to 2-cyclopentenone, $\mathbf{5}^{\prime}$ = aldol product, TS1' = TS structure for

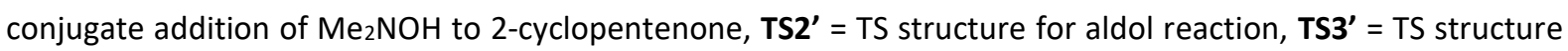
for proton transfer, TS4' $=$ TS structure for $\mathrm{N}$-oxide elimination

Computational methods: All the geometry optimizations and TS structure searches were carried out using the global hybrid meta-GGA M06-2X density functional and 6-311++G(d,p) basis set at $298.15 \mathrm{~K}$ under $1.0 \mathrm{~atm}$ pressure. ${ }^{8}$ The optimized structures were verified as minima or first order saddle points on their potential energy surfaces by harmonic vibrational frequency analysis. The solvent effects of $\mathrm{CH}_{2} \mathrm{Cl}_{2}$ and DMSO on the reaction profile were estimated using the Conductor Polarized Continuum Model (CPCM). ${ }^{9}$ All the energies reported herein are Gibbs free energies (sum of electronic and thermal free energies) expressed in $\mathrm{kcal} / \mathrm{mol}$. Calculations were carried out using the Gaussian 16 suite of programs. ${ }^{10}$

\section{Results and Discussion}

The profile of the $\mathrm{MBH}$ reaction of 2-cyclopentenone with $\mathrm{CH}_{3} \mathrm{CHO}$ under $\mathrm{Me}_{3} \mathrm{~N}$-catalysis is shown in Figure 1 and that of $\mathrm{Me}_{2} \mathrm{NOH}$-catalysis in Figure 2 for comparison. It could be easily inferred that the activation energy of the rate-controlling aldol step is lowered from $41.9 \mathrm{kcal} / \mathrm{mol}$ under $\mathrm{Me}_{3} \mathrm{~N}$-catalysis to $32.6 \mathrm{kcal} / \mathrm{mol}$ under $\mathrm{Me}_{2} \mathrm{NOH}$-catalysis. This reduction in activation energy, $9.3 \mathrm{kcal} / \mathrm{mol}$, is substantial to significantly facilitate the reaction. The activation energy of the conjugate addition step is also lowered by $5.1 \mathrm{kcal} / \mathrm{mol}$, which must be due to the enhanced nucleophilicity of the nitrogen under the $\alpha$-effect of oxygen in $\mathrm{Me}_{2} \mathrm{NOH}$, the cornerstone for the present investigation.

The reaction profile under $\mathrm{Me}_{2} \mathrm{NOH}$-catalysis is distinct from the one under $\mathrm{Me}_{3} \mathrm{~N}$-catalysis in yet another significant aspect. The product $\mathbf{6} \mathbf{b}^{\prime}$ formed from proton transfer is $21.2 \mathrm{kcal} / \mathrm{mol}$ more stable than the aldol product $\mathbf{5}^{\prime}$. This is unlike the $\mathrm{Me}_{3} \mathrm{~N}$-catalysis, wherein the product $\mathbf{6} \mathbf{b}$ is higher on the energy scale than the corresponding aldol product $\mathbf{5}$. Such a steep drop in energy from $\mathbf{5}^{\mathbf{\prime}}$ to $\mathbf{6} \mathbf{b}^{\mathbf{\prime}}$ under 
$\mathrm{Me}_{2} \mathrm{NOH}$-catalysis must thermodynamically push the reaction forward to allow early completion. From TS2' onward, every reaction is a low energy event. The $\mathrm{N}$-oxide elimination is rapid under the reaction conditions for the low energy requirement in comparison to the aldol event.

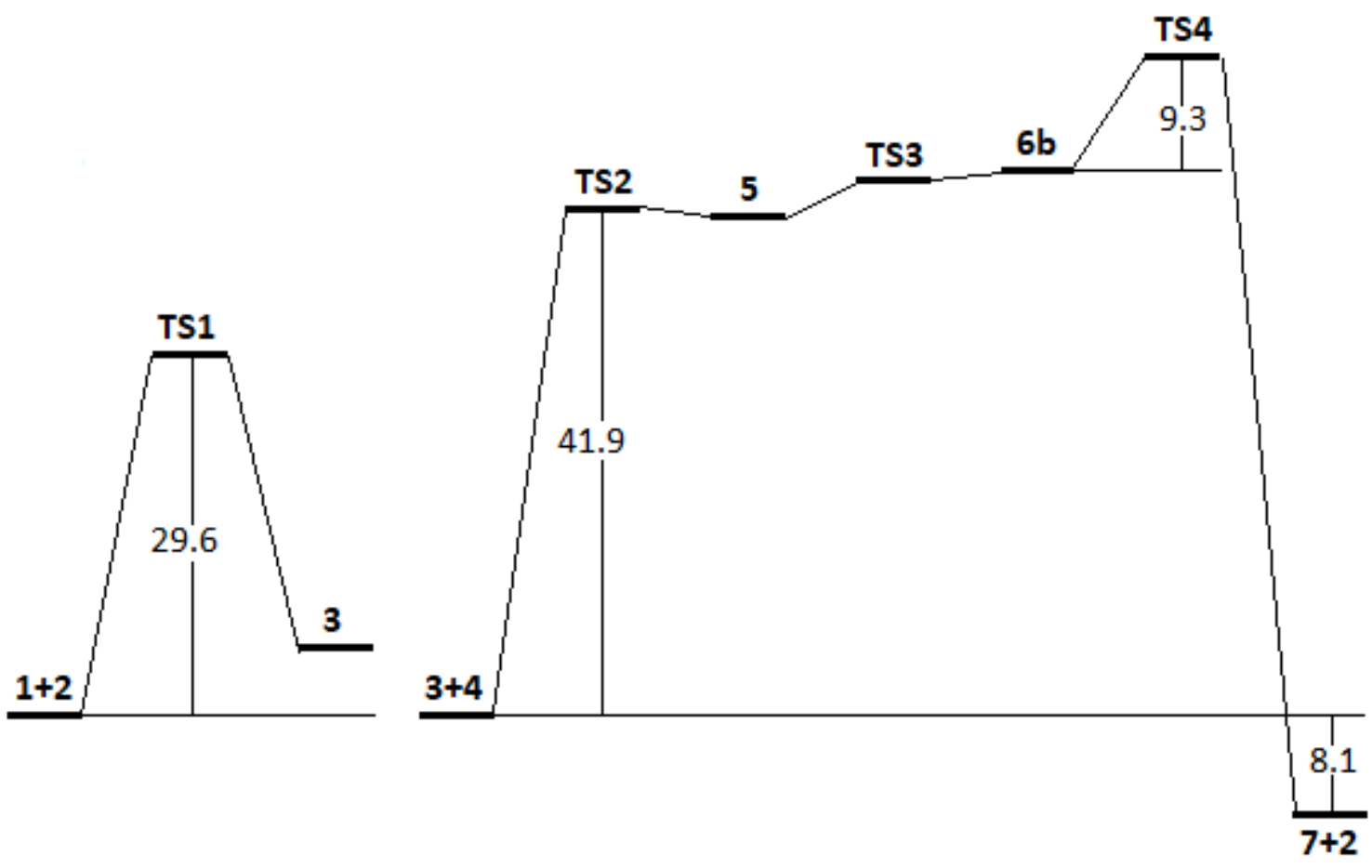

Figure 1. Profile of the $\mathrm{Me}_{3} \mathrm{~N}$-catalysed $\mathrm{MBH}$ reaction of 2-cyclopentenone with $\mathrm{CH}_{3} \mathrm{CHO}$ in the gas phase

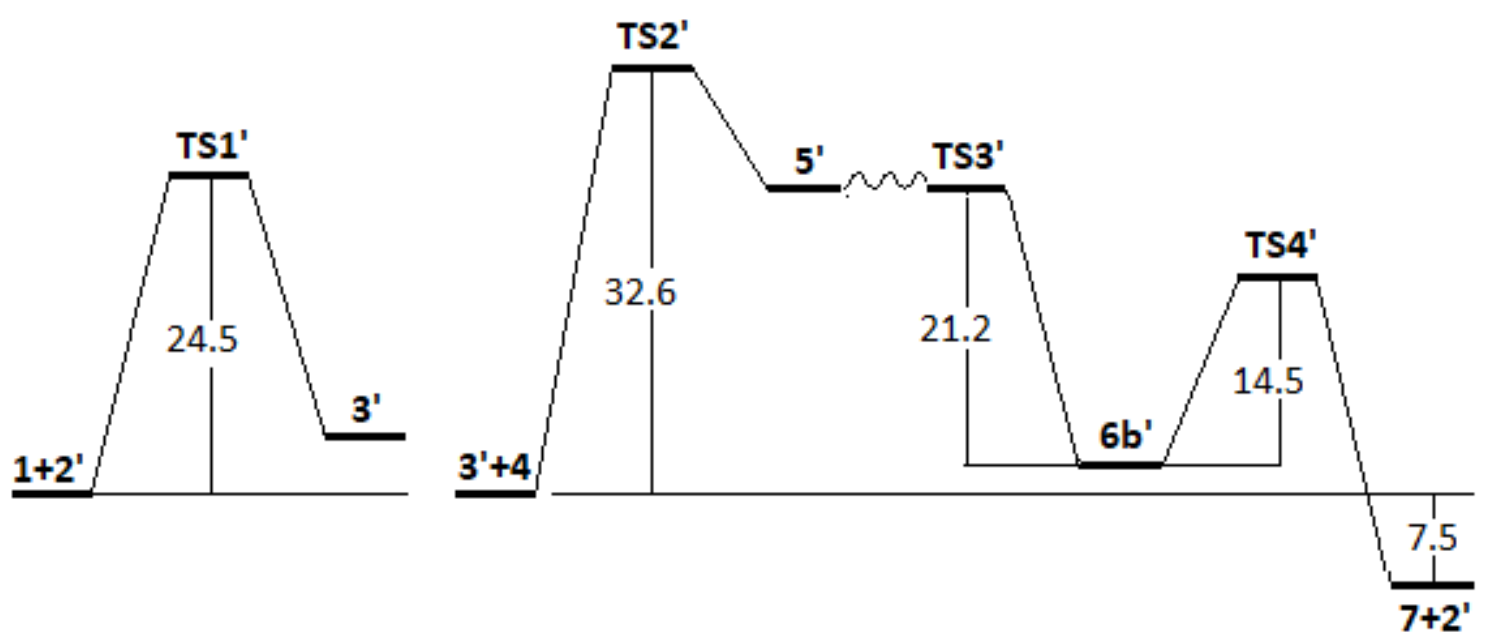

Figure 2. Profile of the $\mathrm{Me}_{2} \mathrm{NOH}$-catalysed $\mathrm{MBH}$ reaction of 2-cyclopentenone with $\mathrm{CH}_{3} \mathrm{CHO}$ in the gas phase

The drop in energy over the transformation $\mathbf{5}^{\mathbf{\prime}} \rightarrow \mathbf{6} \mathbf{b}^{\mathbf{\prime}}$ is likely due to the greater stability of the resultant $\mathrm{N}$-oxide in comparison to the carbon-nitrogen ylide 6 formed under $\mathrm{Me}_{3} \mathrm{~N}$-catalysis. 
An often used organocatalyst for the $\mathrm{MBH}$ reaction is 1,8-diazabicyclo[2.2.2] octane (DABCO), ${ }^{11}$ which has been recognised as more effective than many other tertiary amines. How does $\mathrm{Me}_{2} \mathrm{NOH}$ fare against DABCO? This question arises naturally and must be addressed. The profile of the reaction under DABCO-catalysis is shown in Figure 3. Comparison of the energies of activation of the ratecontrolling aldol reaction reveals that the reaction under $\mathrm{Me}_{2} \mathrm{NOH}$-catalysis is $7.2 \mathrm{kcal} / \mathrm{mol}$ more facile than the reaction under DABCO-catalysis. The conjugate addition of $\mathrm{Me}_{2} \mathrm{NOH}$ to cyclopentenone is also more facile than the addition of DABCO by $3.2 \mathrm{kcal} / \mathrm{mol}$. These observations, taken with the steep drop in energy after proton transfer, $\mathrm{Me}_{2} \mathrm{NOH}$ appears to have the potential of being a more effective catalyst than $\mathrm{DABCO}$ also.

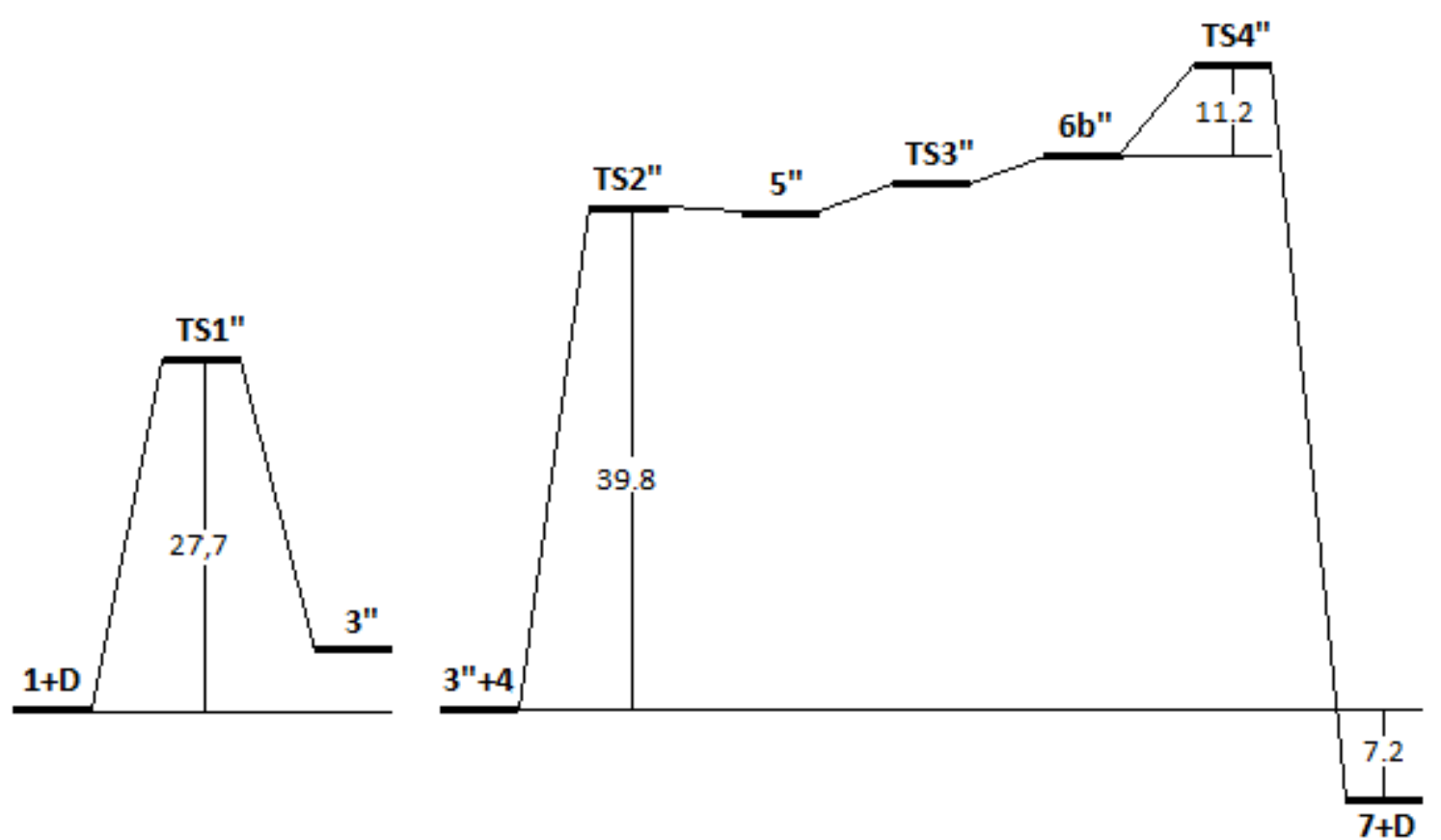

Figure 3. Profile of the $\mathrm{DABCO}$-catalysed $\mathrm{MBH}$ reaction of 2-cyclopentenone with $\mathrm{CH}_{3} \mathrm{CHO}$ in the gas phase. $\mathbf{D}=$ DABCO, TS1" = TS structure for conjugate addition of DABCO to 2-cyclopentenone, $\mathbf{3}$ " = enolate formed from conjugate addition, TS2" = TS structure for aldol reaction, 5" = product of aldol reaction, TS3" = TS structure for proton transfer, 6b" = ylide formed after proton transfer, TS4" = TS structure for Hofmann elimination

The above discussion is applicable to gas phase reactions or reactions under solvent-less conditions, which, at times, have been found to be faster and better yielding than those in solvents. ${ }^{12}$ Since the $\mathrm{MBH}$ reactions are conducted in solvents as well, we chose to study the $\mathrm{Me}_{2} \mathrm{NOH}$-catalysed reaction of 2-cyclopentenone with $\mathrm{CH}_{3} \mathrm{CHO}$ under the solvents effects of dimethyl sulfoxide (DMSO) and $\mathrm{CH}_{2} \mathrm{Cl}_{2}$ to assess whether there was any noticeable change in the reaction profile other than the generally observed facilitation of the aldol reaction. ${ }^{7}$ The reaction profile under the influence of DMSO, Figure 4, is largely similar to that under $\mathrm{CH}_{2} \mathrm{Cl}_{2}$, Figure 5 . The $\mathrm{N}$-oxide formed on proton transfer is sufficiently stable to thermodynamically assist the reaction go forward. As expected, the activation energy of the 
aldol reaction in both instances is lower than in the gas phase, and this may be due to the positive effect of the solvent.

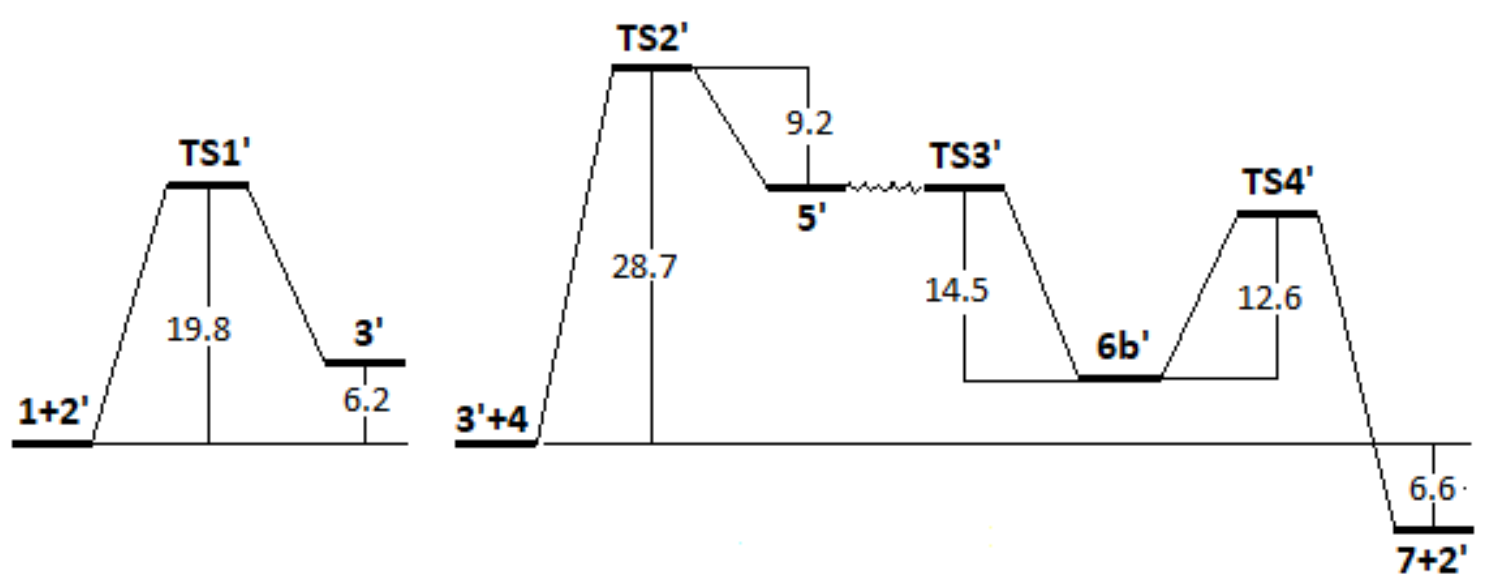

Figure 4. Profile of the $\mathrm{Me}_{2} \mathrm{NOH}$-catalysed $\mathrm{MBH}$ reaction of 2-cyclopentenone with $\mathrm{CH}_{3} \mathrm{CHO}$ under the solvent effects of DMSO.

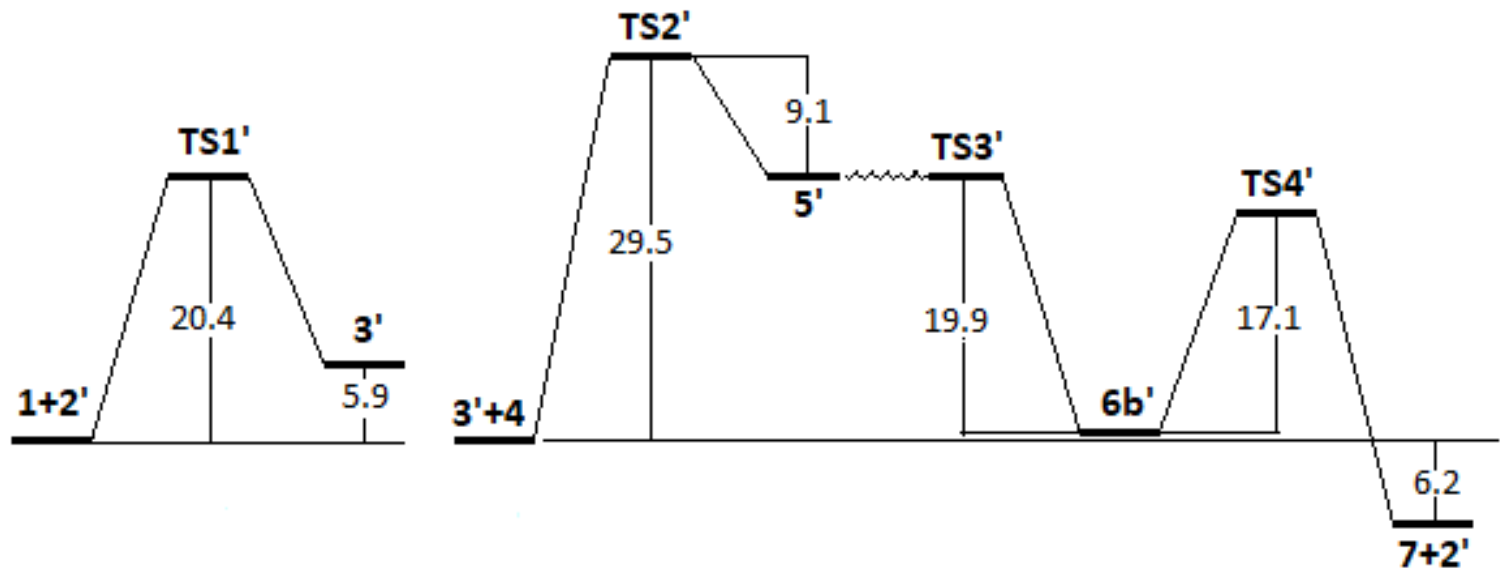

Figure 5. Profile of the $\mathrm{Me}_{2} \mathrm{NOH}$-catalysed $\mathrm{MBH}$ reaction of 2-cyclopentenone with $\mathrm{CH}_{3} \mathrm{CHO}$ under the solvent effects of $\mathrm{CH}_{2} \mathrm{Cl}_{2}$

The energy level of the TS for proton transfer is shown to be the same as the energy level of the aldol product in Figures 1-5. Our attempts at searching this TS structure failed as it always collapsed to the aldol product with vibration in other region of the molecule. We believe that the proton transfer is barrier-less and concurrent with the aldol reaction.

\section{Conclusion}

We have shown from computational investigations in the gas phase and also under the solvent effects of DMSO and $\mathrm{CH}_{2} \mathrm{Cl}_{2}$ that $\mathrm{N}, \mathrm{N}$-dialkylhydroxylamines, such as $\mathrm{Me}_{2} \mathrm{NOH}$, have potential to act as better catalysts than the often used simple tertiary amines, including DABCO, to promote the Morita-BaylisHillman reaction. The $\alpha$-effect of oxygen raises the nucleophilicity of nitrogen, which brings about its relatively more facile conjugate addition to the activated alkene and result in an advanced and, hence, 
more reactive enolate species for the subsequent rate-controlling aldol reaction. The high stability of the $\mathrm{N}$-oxide, formed on proton transfer, provides additional thermodynamic fillip to the reaction for early completion.

\section{ASSOCIATED CONTENT}

\section{Supporting Information}

Supporting Information (SI) available: Cartesian coordinates of the optimized ground state structures, TS structures, Gibbs' free energies of the ground and TS structure.

\section{ORCID}

Veejendra K. Yadav: 0000-0001-8294-0677

\section{ACKNOWLEDGEMENTS}

The author acknowledges allocation of time on HPC series of supercomputers by the Computer Centre, Indian Institute of Technology Kanpur.

\section{References}

1. (a) Morita, K.; Suzuki, Z.; Hirose, H. A Tertiary Phosphine-catalyzed Reaction of Acrylic Compounds with Aldehydes. Bull Chem Soc. Jpn. 1968, 41, 2815-2816. (b) Morita, K.; Kobayashi, T. New Addition Reactions of Acrylic Compounds with Fumaric Acid Esters Catalyzed by Tervalent Phosphorus Compounds. Bull Chem Soc Jpn. 1969, 42, 2732-2732. (c) Baylis, A. B.; Hillman, M. E. D. German Patent 1972, 2155113; Chem. Abstr. 1972, 77, 34174q.

2. (a) Basavaiah, D.; Rao, P. D.; Hyma, R. S. The Baylis-Hillman Reaction: A Novel Carbon-Carbon Bond Forming Reaction. Tetrahedron 1996, 52, 8001-8062. (b) Basavaiah, D.; Rao, A. J.; Satyanarayana, T. Recent Advances in the Baylis-Hillman Reaction and Applications. Chem. Rev. 2003, 103, 811-891. (c) Basavaiah, D.; Rao, K. V.; Reddy, R. J. The Baylis-Hillman reaction: a novel source of attraction, opportunities, and challenges in synthetic chemistry. Chem. Soc. Rev. 2007, 36, 1581-1588. (d) Ma, G.-N; Jiang, J.-J.; Shi, M., Wei, Y. Recent extensions of the Morita-Baylis-Hillman reaction. Chem. Commun. 2009, 5496-5514. (e) Basavaiah, D.; Reddy, B. S.; Badsara, S. S. Recent Contributions from the Baylis-Hillman Reaction to Organic Chemistry. Chem. Rev. 2010, 110, 5447-5674. (f) de Souza, R. O. M. A.; Miranda, L. S. M. Recent Advances in the Morita-Baylis-Hillman Reaction Under Microwave Irradiation Mini Rev Org. Chem. 2010, 7, 212-220. (g) Basavaiah, D.; Veeraraghavaiah, G. The Baylis-Hillman reaction: a novel concept for creativity in chemistry Chem. Soc. Rev. 2012, 41, 68-78. (h) Wei, Y.; Shi, M. Recent Advances in Organocatalytic Asymmetric Morita-Baylis-Hillman/aza-MoritaBaylis-Hillman Reactions. Chem. Rev. 2013, 113, 6659-6690. (i) Bhowmik, S.; Batra, S. 
Applications of Morita-Baylis-Hillman Reaction to the Synthesis of Natural Products and Drug Molecules. Curr. Org. Chem. 2014, 18, 3078-3119. (j) Pellissier, H. Recent developments in the asymmetric organocatalytic Morita-Baylis-Hillman reaction. Tetrahedron 2017, 73, 28312861. (k) Basavaiah, D.; Naganaboina, R. T. The Baylis-Hillman reaction: a new continent in organic chemistry - our philosophy, vision and over three decades of research New J. Chem. 2018, 42, 14036-14066.

3. (a) Robiette, R.; Aggarwal, V. K.; Harvey, J. N. Mechanism of the Morita-Baylis-Hillman Reaction: A Computational Investigation. J. Am. Chem. Soc. 2007, 129, 15513-15525. (b) Carrasco-Sanchez, V.; Simirgiotis, M. J.; Santos, L. S. The Morita-Baylis-Hillman Reaction: Insights into Asymmetry and Reaction Mechanisms by Electrospray lonization Mass Spectrometry Molecules 2009, 14, 3989-4021. (c) Plata, R. E.; Singleton, D. A. A Case Study of the Mechanism of Alcohol-Mediated Morita Baylis-Hillman Reactions. The Importance of Experimental Observations. J. Am. Chem. Soc. 2015, 137, 3811-3826.

4. (a) Yadav, V. K. An alternate energy-conserved pathway for the Morita-Baylis-Hillman (MBH) reaction J. Phys. Org. Chem. 2020 (DOI: 10.1002/poc.4149). (b) Yadav, V. K. A computational study of the Hofmann elimination pathway for the Morita-Baylis-Hillman reaction under DABCO-catalysis. Participation of a bridge-head ylide. J. Phys. Org. Chem. 2021 (DOI: 10.1002/poc.4212)

5. (a) Buncel, E.; Wilson, H.; Chuaqui, C. Reactivity-selectivity correlations. 4. The .alpha. effect in SN2 reactions at sp3 carbon. The reactions of hydrogen peroxide anion with methyl phenyl sulfates. J. Am. Chem. Soc. 1982, 104, 4896-4900. (b) Hoz, S. The .alpha. effect: on the origin of transition-state stabilization. J. Org. Chem. 1982, 47, 3545-3547. (c) Fountain, K. R.; Hutchinson, L. K.; Mulhearn, D. C.; Xu, Y. B. $\alpha$-Effect in Menschutkin alkylations. J. Org. Chem. 1993, 58, 7883-7890. (d) Garver, J. M.; Gronert, S.; Bierbaum, V. M. Experimental Validation of the $\alpha$-Effect in the Gas Phase. J. Am. Chem. Soc. 2011, 133, 13894-13897. (e) Davey, S. Analysing the $\alpha$-effect. Nature Chem. 2011, 3, 753.

6. (a) Hill, J. S.; Isaacs, N. S. Functionalisation of the $\alpha$ position of acrylate systems by the addition of carbonyl compounds: Highly pressure-dependent reactions. Tetrahedron Lett. 1986, 27, 5007-5010. (b) Hill, J. S.; Isaacs, N. S. Mechanism of $\alpha$-Substitution Reactions of Acrylic Derivatives. J. Phys. Org. Chem. 1990, 3, 285-288.

7. For a detailed analysis of the rate-controlling step in MBH reaction, see: Yadav, V. K. (2021): Proton Transfer and Kinetic Isotope Effect in Morita-Baylis-Hillman Reaction Under Solvent Effects. A Detailed Computational Study. ChemRxiv. Preprint. 
8. Zhao, Y.; Truhlar, D. G. The M06 suite of density functionals for main group thermochemistry, thermochemical kinetics, noncovalent interactions, excited states, and transition elements: two new functionals and systematic testing of four M06-class functionals and 12 other functionals. Theor. Chem. Acc. 2008, 120, 215-241.

9. (a) Barone, V.; Cossi, M. Quantum Calculation of Molecular Energies and Energy Gradients in Solution by a Conductor Solvent Model. J. Phys. Chem. A 1998, 102, 1995-2001. (b) Cossi, M.; Rega, N.; Scalmani, G.; Barone, V. Energies, structures, and electronic properties of molecules in solution with the C-PCM solvation model. J. Comput. Chem. 2003, 24, 669-681.

10. Gaussian 16, Revision C.01, Frisch, M. J.; Trucks, G. W.; Schlegel, H. B.; Scuseria, G. E.; Robb, M. A.; Cheeseman, J. R.; Scalmani, G.; Barone, V.; Petersson, G. A.; Nakatsuji, H.; Li, X.; Caricato, M.; Marenich, A. V.; Bloino, J.; Janesko, B. G.; Gomperts, R.; Mennucci, B.; Hratchian, H. P.; Ortiz, J. V.; Izmaylov, A. F.; Sonnenberg, J. L.; Williams-Young, D.; Ding, F.; Lipparini, F.; Egidi, F.; Goings, J.; Peng, B.; Petrone, A.; Henderson, T.; Ranasinghe, D.; Zakrzewski, V. G.; Gao, J.; Rega, N.; Zheng, G.; Liang, W.; Hada, M.; Ehara, M.; Toyota, K.; Fukuda, R.; Hasegawa, J.; Ishida, M.; Nakajima, T.; Honda, Y.; Kitao, O.; Nakai, H.; Vreven, T.; Throssell, K.; Montgomery, J. A., Jr.; Peralta, J. E.; Ogliaro, F.; Bearpark, M. J.; Heyd, J. J.; Brothers, E. N.; Kudin, K. N.; Staroverov, V. N.; Keith, T. A.; Kobayashi, R.; Normand, J.; Raghavachari, K.; Rendell, A. P.; Burant, J. C.; Iyengar, S. S.; Tomasi, J.; Cossi, M.; Millam, J. M.; Klene, M.; Adamo, C.; Cammi, R.; Ochterski, J. W.; Martin, R. L.; Morokuma, K.; Farkas, O.; Foresman, J. B.; Fox, D. J. Gaussian, Inc., Wallingford CT, 2016.

11. (a) Drewes, S. E.; Emslie, N. D. Necic acid synthons. Part 1. Total synthesis of integerrinecic acid. J. Chem. Soc., Perkin Trans. 1, 1982, 2079-2083. (b) Hoffmann, H. M. R.; Rabe, J. Preparation of 2-(1-Hydroxyalkyl)acrylic Esters; Simple Three-Step Synthesis of Mikanecic Acid. Angew. Chem., Int. Ed. Engl., 1983, 22, 795-796. (c) Rabe, J.; Hoffmann, H. M. R. A New, Efficient and Stereocontrolled Synthesis of Trisubstituted Alkenes via Functionalized Acrylic Esters. Angew. Chem., Int. Ed. Engl., 1983, 22, 796-797.

12. (a) Mack, J.; Shumba, M. Rate enhancement of the Morita-Baylis-Hillman reaction through mechanochemistry. Green Chem., 2007, 9, 328-330. (b) Saikia, M.; Sarma, J. C. Baylis-Hillman reaction under solvent-free conditions-Remarkable rate acceleration and yield enhancement. Can. J. Chem., 2010, 88, 1271-1276. (c) R.-Moghadam, K.; Y.-Miri, L. Quick and efficient synthesis of Morita-Baylis-Hillman adducts of isatin derivatives ARKIVOC 2011 (xi) 43-50. 


\section{For Table of Contents}

Computational investigation reveals that the enhanced nucleophilicity of nitrogen due to the $\alpha$ effect of oxygen in $\mathrm{Me}_{2} \mathrm{NOH}$ may significantly raise the facility of Morita-Baylis-Hillman reaction.

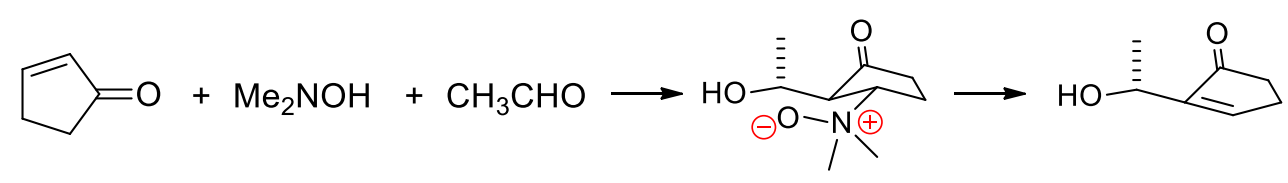

